\title{
BALAI PELAYANAN WARGA
}

\author{
David Pratama ${ }^{1)}$, Sidhi Wiguna Teh ${ }^{21}$ \\ 1)Program Studi S1 Arsitektur, Fakultas Teknik, Universitas Tarumanagara, \\ mail.davidpratama@gmail.com \\ 2)Program Studi S1 Arsitektur, Fakultas Teknik, Universitas Tarumanagara, sidhi@ft.untar.ac.id
}

\begin{abstract}
Abstrak
DKI Jakarta sebagai ibukota dihuni oleh beragam macam masyarakat dari latar belakang yang heterogen. Heterogenitas ini membuat pemerintah DKI sebagai penyelenggara pemerintahan daerah sering tidak sejalan dengan masyarakatnya. Penulis melihat kantor kelurahan di DKI Jakarta memiliki potensi sebagai saluran agar pemerintah dapat menjalin hubungan yang lebih baik dengan masyarakatnya. Kantor kelurahan dapat menjadi wadah yang dicintai dan dekat dengan publik, bila di rancang dengan asas-asas keterbukaan dan fleksibilitas sesuai dengan teori Third Place. Third Place adalah tempat dimana masyarakat dapat beraktivitas bersama secara bebas dan nyaman seperti di rumah. Proyek Balaga adalah proyek re-design kantor kelurahan Sunter Jaya dengan pendekatan teori Third Place dalam perancangannya. Tujuan dari proyek ini adalah mendorong masyarakat dan pemerintah agar dapat saling berkolaborasi dalam memajukan daerahnya. Program awal kantor kelurahan dikembangkan dengan mengikuti kemajuan teknologi, serta programprogram penunjang akan menyesuaikan dengan kebutuhan masyarakat di kelurahan Sunter Jaya. Proyek Balaga yang terletak di sebrang Danau Sunter Barat menjadikan pendekatan proyek ini mengacu pada danau terserbut, Serta kondisi masyarakat sekitar. Dengan adanya balai warga, pusat pelayanan dan fasilitas edukasi, Balaga menjadi meeting point di Danau Sunter Barat serta mengakomodasi masyarakat yang ingin beraktivitas.
\end{abstract}

\section{Kata kunci: Balaga; Kelurahan; Masyarakat; Sunter Jaya; Third Place}

\begin{abstract}
As a capital city with high population density, Jakarta is home to people of heterogenous backgrounds. This drives numerous conflicts between the government and the citizens. The author recognises the potential of community service centres in Jakarta to be a channel in improving the relationship between local government and the local residents. Community service centres could be developed into a familiar and well-loved space, if designed with principles of transparency and flexibility according to the Third Place theories. Third Place can be defined as a space where local residents are able to carry out activities comfortably as they would at home. This project, Balaga, is a project that reimagined the design of community service centre in Sunter Jaya with a Third Place concept approach. The aim of this project is to foster a collaboration between the government and the residents to further develop their local area. Programs that are implemented in this community centre shall adapt to the advancing technology and will be adjusted to suit the needs of users. The Balaga project which is located across West Sunter Lake naturally presents the lake itself and the local dynamic as the project's cornerstone. With functions such as city hall, service centre and educational facilities, Balaga serves as a local meeting point as well as a place to accomodate the activities of the local residents.
\end{abstract}

\section{Keywords: Balaga; Community centre; Public; Sunter Jaya; Third place}




\section{PENDAhULUAN}

Kelurahan adalah ujung tombak dari bentuk pemerintahan yang ada di Indonesia. Saat ini kantor kelurahan menjadi zona yang eksklusif dan formal bagi masyarakat, hanya saat keperluan - keperluan adiministrasi saja warga datang ke kantor kelurahan. Padahal sesuai dengan Peraturan Pemerintah no 73 tahun 2005 tentang kelurahan, mengatakan bahwa kelurahan berfungsi untuk melayani dan memberdayakan warganya.Kondisi ini di perparah dengan tidak sinkronnya visi dan misi dari pemerintah serta keinginan dari warganya, setiap pihak memiliki pemikiran sendiri dan saling menyalahkan satu sama lain.

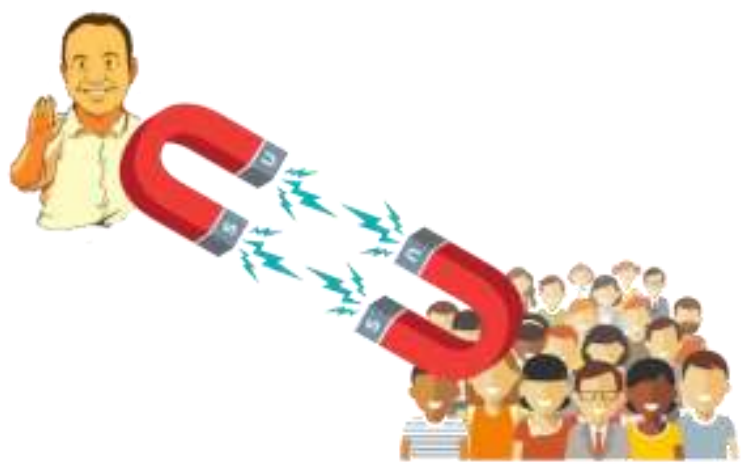

Gambar 1. Ilustrasi masalah pemerintah dan masyarakat Sumber: Hasil olahan penulis, 2020

Pemerintah DKI yang sekarang mulai masuk ke optimalisasi teknologi serta pemerintahan yang terbuka harus dapat mengubah wajah dari kelurahan yang ada sekarang. Kelurahan harus dapat menjadi wadah yang terbuka, nyaman dan dekat dengan warga, Serta menciptakan pemerintahan yang kolaboratif dari warga dan pemerintahan. Kantor kelurahan adalah wadah yang paling sesuai untuk pemerintah untuk melayani dan memberdayakan masyarakat, terdapat 267 kelurahan di Jakarta yang dapat di ubah menjadi tempat yang bebas, nyaman dan menyenangkan dengan tetap menjalankan fungsi kantor kelurahan sebelumnya. Penelitian ini bertujuan menemukan sebuah model baru dari kantor kelurahan dengan menggunakan teori third place sebagai dasar dan mengoptimalisasi fungsi kantor kelurahan yang sudah ada, serta menambahkan fungsi yang dibutuhkan oleh masyarakat. Sasaran akhir dari penelitian ini adalah membuat satu proyek percontohan kantor kelurahan yang bisa di contoh di kantor kelurahan lainnya di DKI Jakarta. Sehingga setiap kelurahan di DKI Jakarta bisa menjadi wadah untuk warganya berkumpul, istirahat dan rekreasi.

\section{KAJIAN LITERATUR}

\section{Ray Oldenburg "Third Place"}

Ray Oldenburg dalam bukunya "The Great, Good Place" mengatakan bahwa Third Place merupakan tempat ketiga yang dibutuhkan oleh masyarakat selain First Place (Tempat Tinggal) dan Second Place (Tempat Bekerja). Third Place merupakan tempat informal yang dijadikan tempat untuk berkumpul, berinteraksi dan bersosialiasi antar sesame manusia. Ray Oldenburg memberikan 8 Kriteria dari Third Place, yaitu :

a. On neutral ground

Sebuah tempat yang netral, dimana setiap individu dapat bebas datang dan pergi. Sebagai tempat publik tidak ada pemiliknya, bebas, netral dari latar belakang apapun. Tidak milik siapapun namun juga terasa dimiliki oleh semuanya.

b. The third Place as leveller

Tempat yang inklusif untuk siapa saja, Menjadi tempat untuk berkumpul, bersosialisasi dan berinteraksi tanpa melihat latar belakang. Jabatan, pekerjaan tidak dilihat. Semua setara dan memiliki hak yang sama. 


\section{c. Conversation is the main activity}

Kegiatan utama dari Third Place ini adalah komunikasi antara individu satu dan yang lainnya. Komunikasi tidak harus memiliki sebuah topik atau tujuan tertentu. Komunikasi dijalin untuk saling bertukar pikiran, mengenal satu sama lain agar setiap individus saling toleran.

d. Accessbility and accommodation

Kemudahan akses masyarakat menuju Third Place menjadi keharusan. Masyarakat harus bisa mengakses dan terakomodasi dengan mudah ke kedalam Third Place.

e. The regulars

Third Place harus memiliki Pengunjung tetap, untuk meciptakan rasa penerimaan dalam Third Place, untuk terus membuat tempat public terus hidup. The Regulars hanya menjadi pengunjung tetap tidak menjadikan Third place menjadi teritori mereka.

f. A low profile

Third Place secara fisik harus menerima masyarakatnya, terlihat menyambut dan tidak menyombongkan diri. Harus sesuatu yang dikenal oleh masyarakat bukan sesuatu yang aneh dan baru sehingga masyarakat enggan untuk masuk ke Third Place.

g. The mood is Playful

Mood dan Perasaan yang dimiliki oleh Third Place harus playful, Suasana yang dirasakan oleh pengunjung saat masuk Playful, ceria, nyaman untuk membangkitkan semangat dan mood lainnya.

h. A home away from home

Walaupun Third Place bukan lah rumah seperti First Place, tetapi Perasaan akan nyamannya Rumah secara psikologis harus dimiliki oleh Third Place, Perasaan ini yang membuat Third Place selalu membuat ingin kembali lagi seperti rumah.

Berdasarkan Teori Ray Oldenburg tentang Third Place, dapat dilihat bahwa untuk menciptakan Third Place diperlukan 8 Kritetia yang sudah dijelaskan. Agar tempat tersebut bisa dianngap sebagai Third Place yang benar.

\section{Edward Soja "Third Space"}

Edward Soja mengembangkan teori "Third Space" dimana semuanya melebur menjadi satu, subjektifitas dan objektifitas, abstrak dan nyata, asli dan imajinasi, diketahui dan tidak diketahui, sama dan berbeda, pikiran dan tubuh, kehidupan sehari-hari dan sejarah. Third space menjadi tempat dimana semuanya di negosiasi ulang, Semuanya kemungkinan masih terbuka tanpa batasan. Third Space adalah tempat yang Hybrid, dimana memungkinkan semuanya terjadi. Berhubungan dengan teori Heterotopia yang membentuk space asli dan maya dalam realitasnya. Dalam konsep Hybrid Third Space adalah gabungan dari variable tetap (fisik) dan variable bebas (remote) yang di pengaruhi oleh banyak pengguna bebas (third space). Contoh nya : Starbucks sebagai café (Variable tetap fisik) memiliki banyak meja (Variable bebas remote) untuk digunakana. Hubungan antar meja secara tidak langsung ini menimbulkan sebuah "norma" untuk bisa saling berhubungan dengan menggabungkan meja untuk interaksi maupun untuk tidak saling berhubungan dengan tidak berbicara terlalu berisik untuk menghormati meja sebelahnya (Third space).

\section{J.F.Moore "The Art of Third Place"}

J.F.Moore dalam Thesisnya "The Art of the Third Place" mempertanyakan bagaimana Place bisa dianggap sukses, Menurut Moore cara unutk melihat kesuksesan Place adalah Manusia. Manusia yang datang dan beraktivitas menjadi tolak ukur kesuksesan suatu Place, Kalau kita mendesign untuk Manusia namun tidak ada manusianya maka itu adalah kegagalan. Moore juga memberikan 9 Kriteria untuk menciptakan Third Place yang sukses yaitu:

a. Architectural Relationship

Hubungan antara Third Place dengan Arsitektur sekitarnya, Fungsi dari Arsitektur adalah pendorong untuk menuju ke sebuah tempat. Bagaimana Skala menjadi penghubung antar 
manusia dengan Arsitektur, Bagaimana arsitektur menciptakan ruang yang nyaman bukan ruang mati.

b. Permeability

Permeabilitas dari third place, Pergerakan manusia dari satu tempat ke tempat lainnya, kemudahan dan kenyamanan dari pergerakan orang melalui third place ini. Pengalaman ruang yang dirasakan dari jalanan menuju third place. Tempat dengan permeabilitas yang tinggi menjadi kunci dari kesuksesan sebuah third place.

c. Legibility

Bagaimana sebuah Third Place dapat dengan mudah terbaca oleh penggunanya. Sebuah Third Place harus dapat terbaca maknanya oleh penggunanya dari segi fungsi, ruang dan tujuan third place itu. Hal ini dapat dikenali melalui path, nodes, edges, landscape, furniture, pengalaman ruang.

d. Linkages and Sequencing

Sebaik apakah Third place terhubung dengan penggunanya ? Apakah hubungan antara third place dan penggunanya menciptakan pengalaman spasial ruang ? Apakah pengalaman ini berdasarkan rangkaian ruang yang di lewati ? Pengalaman ruang seharusnnya bisa menjadi nilai jual yang dibuat oleh ruang-ruang yang ada di dalam third place. Setiap pengguna harus bisa merasakan keseluruhan ruang yang ada tanpa ada ruang yang dianggap jelek atau mati.

e. Safety Factors

Rasa aman adalah faktor yang harus dimiliki oleh sebuah third place. Sebagai sebuah tempat baru yang menerima setiap individu dan memberikan kenyamanan. Rasa aman adalah perasaan yang harus dimiliki saat individu berada dalam third place, setiap individu bisa merasa tenang dan tidak memikirkan apa yang ada di rumah, di kantor, ancaman, intimidasi, penghakiman. sehingga setiap individu bisa bebas menjadi dirinya sendiri.

f. Activities

Kegiatan Multifungsi yang beragam menjadi pusat daya tarik yang membuat orang ingin beraktifitas di suatu tempat. Third place harus menyediakan beragam macam aktifitas yang bisa menggapai berbagai macam kalangan dalam satu tempat. Beragam aktifitas ini yang menjadi jaminan keamaan bahwa third place bisa berhasil.

g. Hybridity and Adaptibility

Hybridity dan Adaptibilitas sebuah tempat sangat kuat kaitannya dengan kebutuhan tempat dan keberagaman aktifitas yang dapat diwadahinya. Sebuah Thirdplace harus bisa adaptif dengan lingkungannya dan mengakomodasi bermacam aktifitas yang diperlukan.

h. Comfort and Personalisation

Kenyamanan sebuah third place harus berorientasi dengan lingkungan sekitarnya. Pengguna harus merasakan third place sebagai tempat yang personal seolah mereka memiliki "tempat"nya dan merasa third place sebagai "tempat"nya. Rasa nyaman dan personal ini harus bisa di dapat dengan mudah dan langsung diterima.

i. The Experiental Landscape

Pengalaman Ruang dalam third place harus saling terhubung dan memiliki kesan yang membekas. Third place harus bisa menghadirkan pengalaman yang menyatu, tidak hanya bangunan tetapi juga menyatu dengan lingkungan sekitarnya. Kesatuan Pengalaman ini tidak lepas dari transisi, arahan dan design dari sebuah third place.

Pemenuhan 9 Kriteria ini diharapkan dapat menciptakan third place yang berhasil dan sukses, baik secara program tepat sasaran juga secara intensitas pengguna yang banyak, sehingga third place menjadi hidup dan berdampak.

\section{Kantor Kelurahan}

Kelurahan adalah wilayah kerja lurah sebagai perangkat daerah kabupaten/kota di bawah kecamatan yang berada di bawah dan bertanggung jawab kepada camat. Kelurahan mempunyai 
tugas dan fungsi melaksanakan kewenangan pemerintahan yang dilimpahkan oleh Camat serta melaksanakan tugas pemerintahan lainnya sesuai ketentuan perundangan yang berlaku. Hubungan kerja kecamatan dengan kelurahan bersifat hierarki. Pembentukan kelurahan ditujukan untuk meningkatkan kemampuan penyelenggaraan pemerintahan kelurahan secara berdayaguna, berhasilguna dan pelayanan terhadap masyarakat sesuai dengan tingkat perkembangan dan kemajuan pembangunan.

Kelurahan dilihat dari sistem pemerintahan Indonesia merupakan ujung tombak dari pemerintahan daerah yang langsung berhadapan dengan masyarakat luas. Citra birokrasi pemerintahan secara keseluruhan akan banyak ditentukan oleh kinerja organisasi tersebut. Masyarakat perkotaan yang peradabannya sudah cukup maju, mempunyai kompleksitas permasalahan lebih tinggi dibandingkan dengan masyarakat tradisional sehingga diperlukan aparatur pelayanan yang profesional. Oleh karena itu, dirumuskan visi, misi, strategi dan nilai acuan pemerintah yang menjadi pedoman mengenai arah yang dituju, beban tanggung jawab, strategi pencapaiannya serta nilai-nilai sikap dan perilaku pegawai. Untuk mencapai tujuan tersebut aparatur kelurahan di tuntut untuk memberi suatu kualitas pelayanan yang prima tercermin dari transparansi, akuntabilitas, partisipasi, kesamaan hak, dan keseimbangan hak dan kewajiban.

\section{METODE}

Proyek tugas akhir ini melalui beberapa proses dalam metode perancangannya, yang di jelaskan dalam diagram dibawah ini:

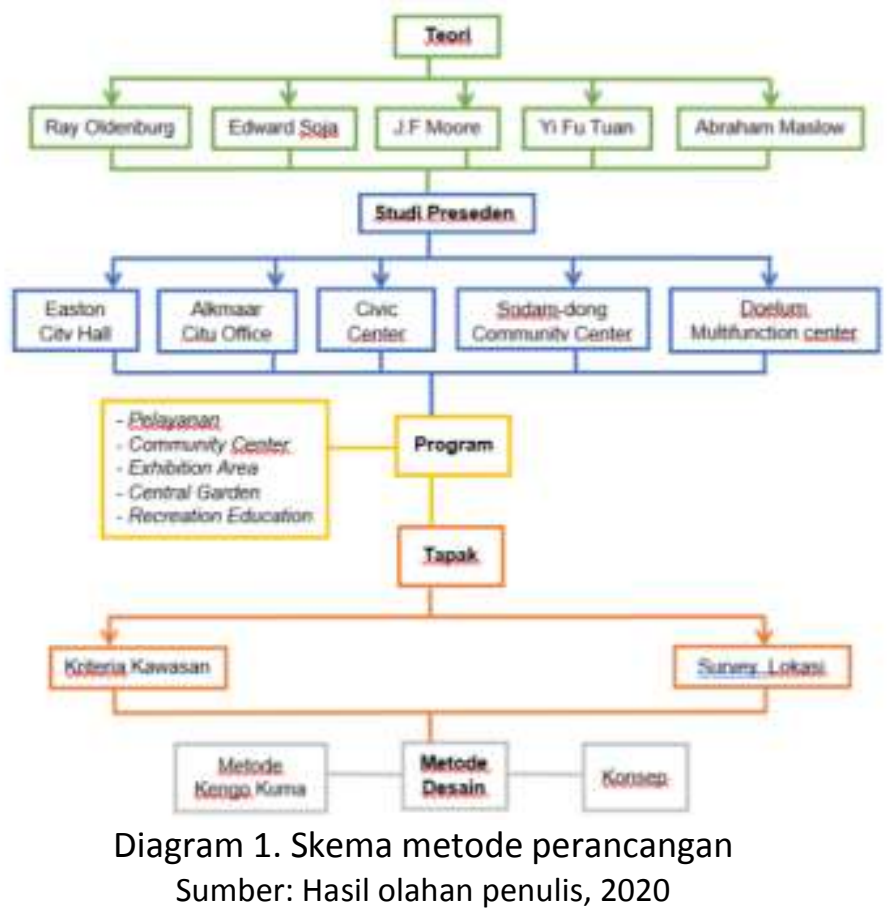

Tahapan design dimulai dari pemahaman teori mengenaik third place yanng dilanjutkan dengan mempelajari preseden yang sudah ada, untuk menghasilkan program bangunan yang sesuai. Lalu dilanjutkan ke pemilihan tapak yang sesuai dengan teori dan program yang diajukan hingga akhirnya masuk ke dalam proses perancangan. Metode desain yang di gunakan mengadaptasi dari metode design kengo kuma yang menginspirasi dan sesuai dengan proyek yang akan di jalankan.metode tersebut meliputi :

\section{a. Modesty}

Dalam proses berarsitektur, Seorang Arsitek harus bisa menghargai setiap proses. Arsitek harus bisa Humble dan bekerja secara perlahan bergerak satu persatu dari visi kecil menuju 
visi yang lebih besar, tidak ada jalur yang instan. Desain juga seperti itu, Desain harus bisa sopan dan jujur terhadap lingkungannya sehingga apa yang diinginkan arsitek dapat tergambarkan dalam Arsitekturnya.

b. Physichal Experience

Dalam setiap proyek, Kuma selalu berjalan ke tapak dan merasakan langsung realita yang ada di dalam tapak juga memori yang tersimpan di dalam tapak tersebut. Merasakan langsung dan hadir ke tapak adalah titik awal mula bagaimana berbicara dan berinteraksi dengan tapak.

c. Relationship between Architecture, Space and Time

Hubungan Arsitektur dengan tempat juga dengan waktu, Bagaimana sebuah arsitektur hadir sebagai sebuah monument baru di tempatnya lalu perlahan berubah menjadi lingkungan itu sendiri. Waktu selalu terus berjalan dan Arsitektur harus bisa menjadi bagian yang berjalan.

\section{DISKUSI DAN HASIL}

BALANGA diambil dari kata Belanga yang berarti wadah besar untuk memasak berbagai macam sayuran, secara filosofi proyek ini adalah tempat bertemu warga dari berbagai macam latar belakang untuk saling berinteraksi. Sama seperti sayur-sayuran yang di campurkan di dalam satu panci belanga. BALANGA adalah proyek Re-Design Kantor Kelurahan Sunter Jaya. Proyek ini bertujuan menjadikan Bangunan Pemerintah menjadi Third Place bagi warga sekitarnya. Sesuai sejarahnya Bangunan Pemerintahan di Indonesia adalah wadah yang bebas dan ramah bagi warganya. BALANGA sebagai Third Place menjadi titik temu dari warga dan pemerintah, Mengubah wajah pemerintah menjadi lebih terbuka, fleksibel dan kolaboratif dengan warganya. BALANGA hadir sebagai wadah untuk warga berkumpul, bermain, belajar, istirahat serta berkolaborasi dengan Pemerintah untuk memajukan Kelurahan Sunter Jaya. BALANGA menjadi meeting point, entry gate, serta penunjang aktvitas Public Space Danau Sunter Barat. Intensitas pengguna yang tinggi dan kebebasan untuk digunakan siapa saja menjadikan BALANGA menjadi wadah pertukaran informasi antara warga dan pemerintah menjadi lebih tepat, cepat dan terbuka.

\section{Skema Perancangan}
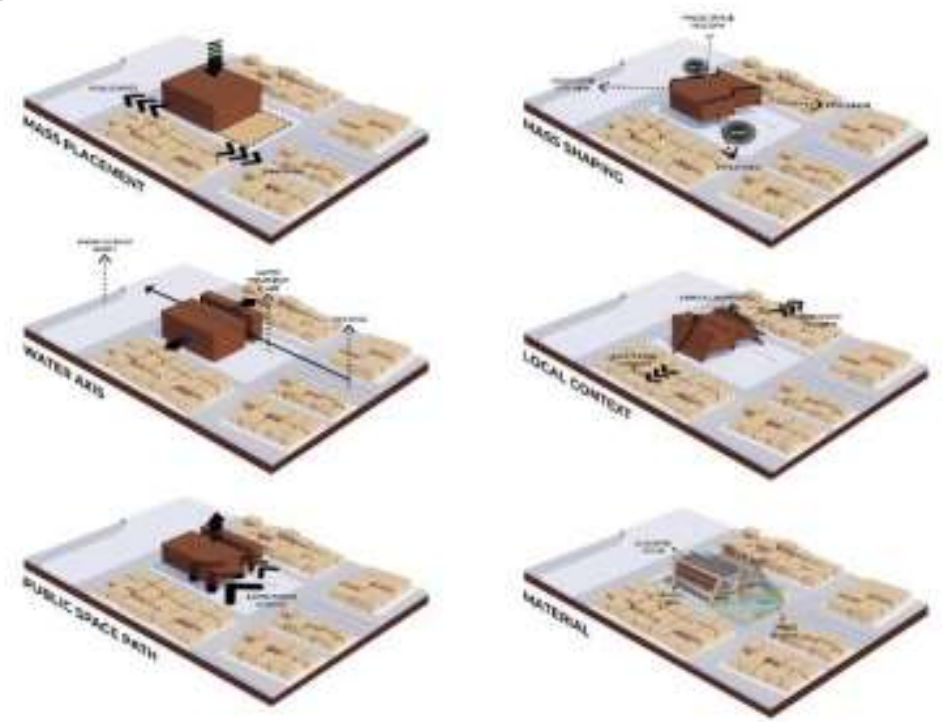

Gambar 2. Skema Perancangan Balaga

Sumber: Hasil olahan penulis, 2020

Skema perancangan proyek ini mengedepankan kebutuhan dari tapak dan sekitarnya. Skema ini dirancang sesuai dengan respon dari lingkungan tapak yang ada, kelokalan masyarakat yang tinggal di sekitar tapak dan juga bagaimana kehadiran proyek ini di tengah lingkungan 
masyarakat tidak menjadi penganggu dari kegiatan masyarakat yang sudah ada sebelumnya. Kehadiran proyek ini harus meningkatkan kualitas dari aktivitas masyarakat yang ada di lingkungan tapak.

\section{Zonasi}
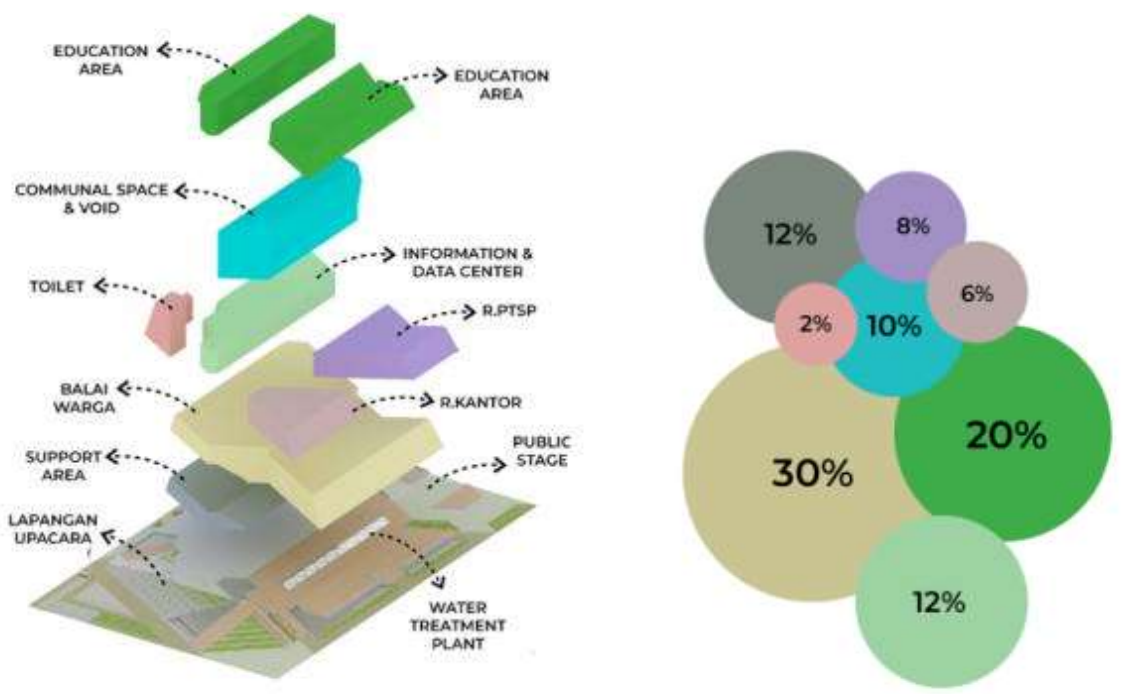

Gambar 3. Zoning bangunan dan persentase zoning

Sumber: Hasil olahan penulis, 2020

Zoning bangunan di susun dengan mengedepankan aksebilitas dari kebutuhan program dari bangunan yang sudah ada serta menyesuaikan kondisi tapak yang memiliki akses dari segala arah bangunan. Zoning bangunan secara garis besar terbagi menjadi Zona bawah dan Zona atas. Zona bawah terdiri dari support area, dimana sistem MEP bangunan di olah dan juga balai warga sebagai tempat warga berkumpul dan sirkulasi utama menuju public space danau sunter barat. Zona atas bangunan merupakan zona indoor dari proyek ini yang membutuhkan kenyamanan dari segi cahaya, penghawaan, visual dan audial. Zona atas terdiri dari zona pelayanan kelurahan meliputi PTSP dan data center serta zona edukasi untuk masyarakat berdiskusi, belajar dan bekerja.

\section{Konsep Bangunan}

Proyek Balaga memiiliki beberapa konsep dalam konteks urban dari bangunan ke sekitarnya, konsep ini disesuaikan dengan teori dan kebutuhan masyarakat yang ada, konsep bangunan ini meliputi: 


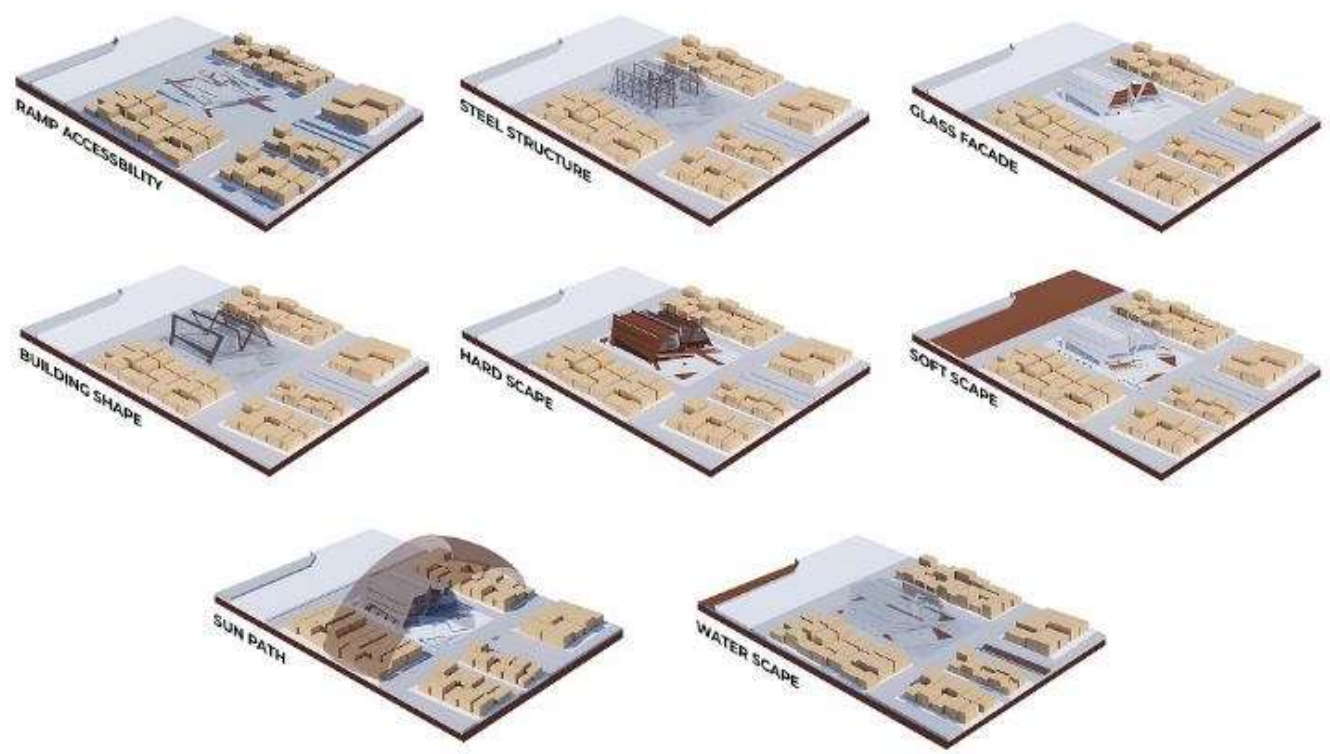

Gambar 4. Konsep bangunan

Sumber: Hasil olahan penulis, 2020

\section{a. Entrance}

Bangunan dikelilingi oleh 4 sisi jalan yang dilalui oleh kendaraaan. Bangunan mengusung konsep open architecture untuk segala kalangan bisa datang dan mudah mengakses ke bangunan. Maka dari itu bangunan di buat dapat diakses dari 4 sisi jalan yang ada di samping bangunan

b. Breathable

Tapak berada di dekat danau yang menjadi ciri dari kawasan sunter jaya. untuk memasukan suasana dari danau maka bangunan di buat breathable dengan menggunakan fasad yang dapat melakukan pertukaran udara. Sehingga bau dan rasa dari danau dapat masuk ke dalam bangunan.

c. Sunpath

Bangunan berorientasi ke arah utara, sehingga sisi timur dan barat mendapat paparan sinar matahari lebih lama yang membuat bangunan menjadi panas. Maka dari itu sisi timur barat digunakan fasad solid sedangkan sisi utara selatan menggunakan fasad transparan untuk memaksimalkan cahaya alami yang masuk ke dalam bangunan.

d. Accessbility

Aksesbilitas di dalam bangunan menggunakan ramp sebagai sirkulasi utama. hal ini untuk mendukung teori dari third place sebagai tempat netral. Sehingga baik disabilitas maupun orang biasa memiliki pengalaman ruang yang sama dalam mengakses setiap lantai bangunan.

e. Building shape

Bentuk bangunan diadaptasi dari bentuk atap tradisional indonesia. Bentuk ini sudah di kenal masyarakat serta juga bentuk ini memperhatikan kenyamanan jarak pandang warga yang tinggal di sekitar bangunan. Maka dari itu sisi vertikal bangunan semakin tinggi semakin dijauhkan dari pemukiman warga, sehingga membentuk sudut dinding sekaligus atap bangunan.

f. Visibility

Visibiltas bangunan di arahkan dengan aksis utara selatan, dimana danau pada sisi selatan dan pemukiman di sisi utara, sehingga visibilitas warga tidak terhalang oleh bangunan yang ada. Warga tetap bisa melihat serta mengakses danau melalui lantai dasar bangunan yang dibuat menjadi open space dengan bentang lebar.

g. Softscape

Softscape bangunan menggunakan material utama berupa paving. Material ini dipilih karena 
memungkinkan terjadinya perkerasan namun air tetap dapat masuk ke dalam tanah langsung.

h. Waterscape

Pada tapak terdapat axis air dari saluran air dan danau sunter barat. Untuk meneruskan axis tersebut maka pada bangunan di letakan water treatment plant yang diekspose dengan bahan kaca transparan, sehingga seolah-olah axis dari kali ke danau diteruskan melalui lantai dasar bangunan.

i. Public space

Bangunan dan public space danau sunter barat di tengahi oleh jalanan umum dimana kendaraan dapat berlalu lalang. Maka dari itu, jalan di tengah tersebut di ubah dengan perubahan peil serta material yang berbeda. Agar pengguna jalan memiliki perhatian lebih bahwa pada jalan ini berbeda dan lebih sering di lalui oleh warga, sehingga pengguna kendaraan lebih berhati-hati.

\section{Konsep Struktur}

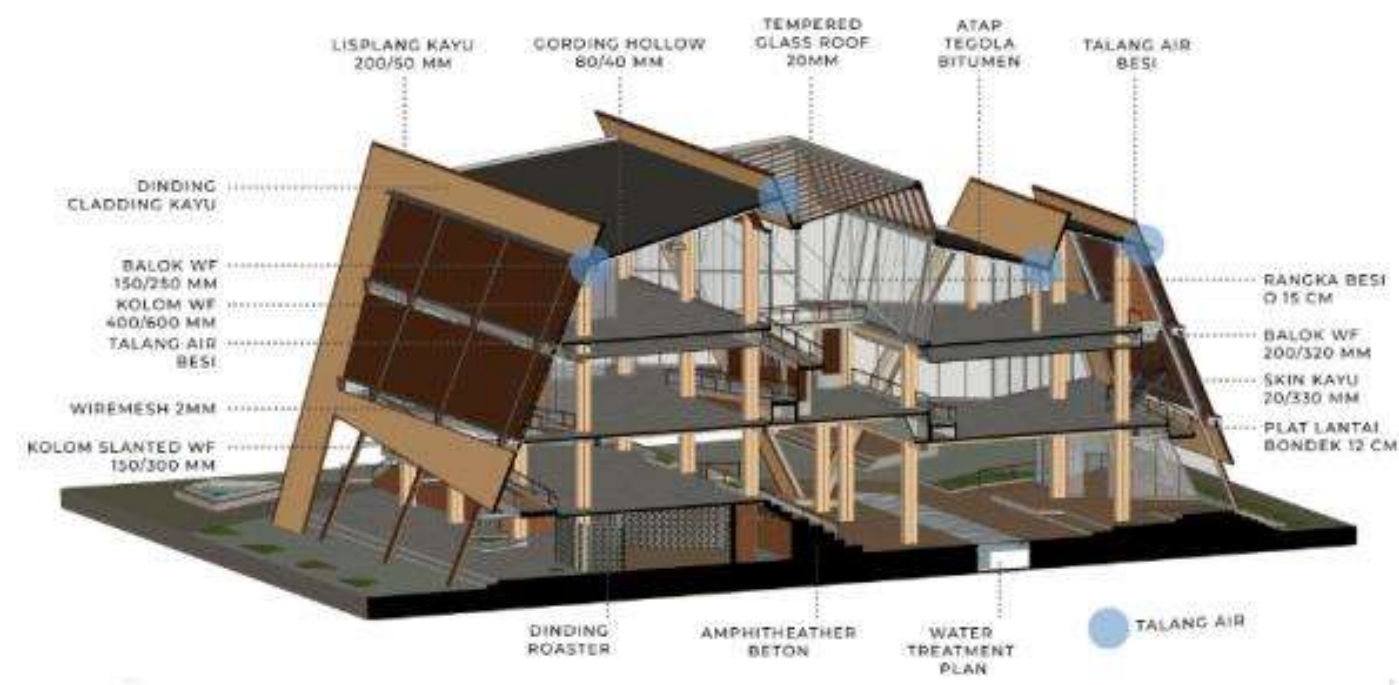

Gambar 5. Potongan Perspektif bangunan

Sumber: Hasil olahan penulis, 2020

Struktur Bangunan ini menggunakan Struktur Baja sebagai sistem struktur utama. Penggunaan struktur baja ini dipilih dengan mempertimbangkan 3 hal, yaitu:

a. Kecepatan

Proyek ini adalah proyek re-design bangunan pelayanan publik, sehingga dibutuhkan dalam waktu cepat agar proses pelayanan bisa berlangsung dengan baik. Stuktur baja memungkinkan proses karena sudah dibuat jadi dan sambungan menggunakan mur baut yang lebih cepat dan mudah.

b. Kualitas

Kualitas dari baja yang digunakan lebih stabil daripada menggunakan struktur beton biasa. Pembuatannya di pabrik sudah melalui proses quality control sebelum sampai ke proyek.

c. Bentang Lebar

Kebutuhan proyek untuk bentangan lebar di daerah balai warga dapat di penuhi oleh struktur baja untuk memaksimalkan efektivitas ketinggian ruang yang di dapat. 


\section{Konsep Fasad}

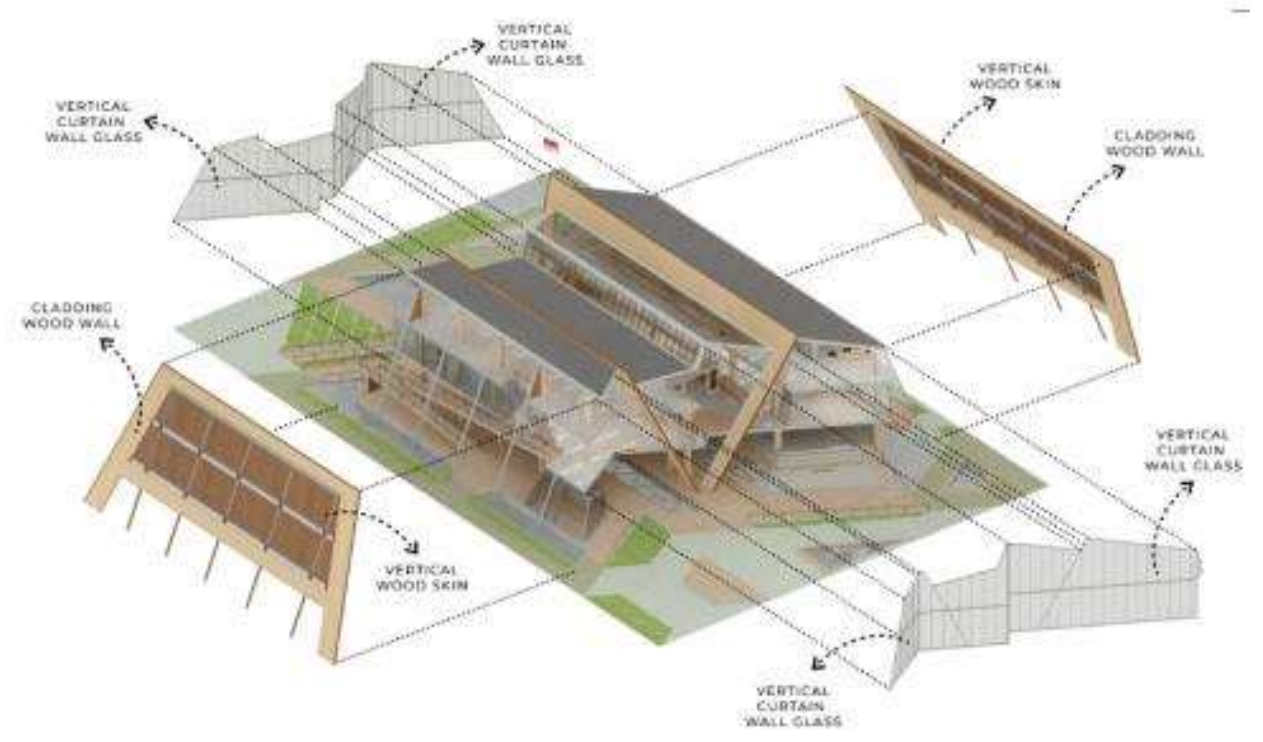

Gambar 6. Explode fasad bangunan

Sumber: Hasil olahan penulis, 2020

Fasad bangunan di olah sesuai dengan orientasi bangunan, dimana bangunan menghadap ke arah utara. Sehingga untuk meminimalisir papaparan sinar matahari secara langsung, pada sisi timur dan barat bangunan memnggunakan fasad solid dengan skin kayu untuk menyaring sinar matahari untuk masuk ke dalam bangunan. Sedangkan sisi utara dan selatan bangunan menggunakan fasad transparan untuk memaksimalkan cahaya matahari tidak langsung ke dalam bangunan. Sisi Transparan fasad juga berarti ingin membiarkan masyarakat untuk bisa melihat ke dalam sebagai bentuk pemerintahan yang transparan, serta memaksimalkan view di sisi utara mengarah ke danau sunter barat.

\section{Third Place}

Proyek ini adalah proyek third place, dimana third place adalah teori yang di cetuskan oleh Ray Oldenburg mengenai tempat ketiga manusia, dimana third place menjadi tempat yang bebas dan netral bagi semua orang. Menurut Oldenburg third place memiliki 8 kriteria perancangan. Proyek balai pelayanan warga sunter jaya ini sudah mengikuti 8 kriteria perancangan tersebut, yaitu :

\section{a. On neutral ground.}

Proyek ini berada dalam zona pemerintahan daerah, serta berfungsi sebagai bangunan pemerintahan. Indonesia adalah negara hukum yang menjamin kesetaraan penduduknya sama di dalam hukum dan pemerintah adalah penjalan kebijakannya. Maka dari itu bangunan pemerintah menjadi zona paling netral untuk seluruh warga negara Indonesia.

b. Third place as leveler.

Ramp menjadi Sirkulasi utama di dalam proyek ini, Ramp digunakan untuk menghubungkan dari lantai ke lantai dan di tonjolkan pada interior bangunan sebagai ciri dan karakter bangunan. Penggunaan Ramp ini menjadikan bangunan ini sebagai Leveler untuk segala kalangan baik disabilitas maupun tidak.

c. Conversation is the main activity.

Proyek ini menjadi wadah untuk warga sunter jaya untuk berkumpul, berbicara, ngobrol satu sama lainnya. Pada proyek ini Arsitektur sebagai wadah aktifitas nya dari arisan, rapat, belajar, pelayanan. Lalu Budaya orang Indonesia yang suka berinteraksi, berbicara di tempatkan pada wadah (proyek) ini. sehingga Conversation menjadi aktifitas utama dalam proyek ini. 


\section{d. Accessibility and accomodation.}

Aksesbilitas menuju tapak dapat dilalui dari seluruh sisi proyek (multi akses) untuk memudahkan akses untuk warga sunter jaya dari pemukimannya dan dan dari public space danau sunter barat. Proyek juga mengakomodir seluruh lapisan masyarakat baik kelas menengah maupun atas dengan menjadi meeting point / gate dari public space danau sunter barat.

e. The regulars.

Proyek ini menjadi Meeting Point dari Public Space Danau Sunter Barat. Proyek ini juga menjadi Gate sebagai awal dan akhir saat warga ingin menuju ke public space danau sunter barat. Maka pengguna dari publik space ini akan menjadi regulars ke proyek ini sebagai titik temunya.

f. A low profile.

Proyek ini Kontekstual dengan kondisi sekitar tapak dengan sopan pada bangunan sekitarnya. Dengan membuka lantai dasar sebagai open space, juga view arah utara selatan di "open" dengan fasad kaca untuk sehingga dri pemukiman tetap bisa melihat ke arah danau. Bentuk Bangunan juga diadaptasi dari bentuk tradisional bangunan Indonesia dengan atap miringnya, sehingga tidak menjadi benda aneh di masyarakat.

g. The mood is playful.

Playful mood dari proyek ini berusaha dibangun dengan membagi bangunan dengan Split Level sehingga memberikan pengalaman sirkulasi yang berbeda pada setiap lantainya. Keberadaan Ramp, Void, Amphitheater pada bangunan membuat bangunan menjadi lebih luas, bebas, dan memiliki pengalaman yang berbeda dalam setiap eksplorasi ruang yang ada di proyek ini.

h. A home away from home.

Proyek ini memiliki skala pelayanan kelurahan, juga berada dalam jarak jangkauan masyarakat sunter jaya. berada pada jalan yang setiap harinya dilewati saat ingin pergi maupun pulang. menjadikan Proyek ini menjadi bagian yang tidak terpisahkan dari Lingkungan "Rumah" warga sunter jaya.

\section{KESIMPULAN DAN SARAN}

Balai Pelayanan Warga (Balaga) Sunter Jaya adalah karya arsitektur yang di bangun untuk menciptakan sebuah wajah baru untuk kantor kelurahan yang terbuka, aktif dan kolaboratif. Proyek ini memiliki konsep thirdplace untuk warga kelurahan sunter jaya yang memicu kolaborasi aktif antara warga dan pemerintah dalam membangun daerahnya, sehingga visi dan misi pemerintah dapat berjalan bersamaan dengan keinginan masyarakatnya.

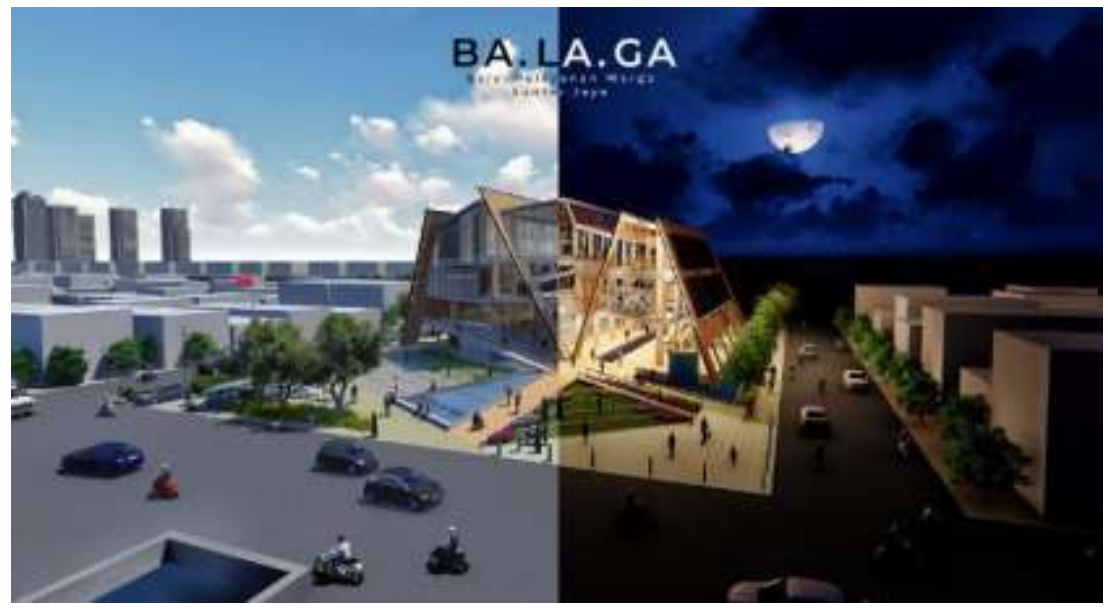

Gambar 7. Perspektif Balaga

Sumber: Hasil olahan penulis, 2020 
Program Balaga terdiri dari 3 program utama yang di buat untuk meningkatkan kualitas masyarakat tinggal di kawasan sunter jaya. Pertama, Program balai warga dimana warga memiliki komunal space untuk beraktivitas, ngobrol dan beristirahat, juga menjadi tempat warga bertemu satu sama lain dan mengenal lingkungannya. Kedua, Program pelayanan warga dari program kantor kelurahan yang tidak hanya melayani secara administatif namun juga melayani kebutuhan lain masyarakat. Ketiga, Program edukasi untuk warga belajar, bekerja dan meningkatkan kemampuannya, Program ini menjadi penting agar masyarakat teredukasi dan memahi visi dan misi dari pemerintah secara luas dan objektif. Proyek Balaga ini bisa menjadi proyek percontohan untuk kantor kelurahan yang lainnya di Jakarta, menguatkan fungsi pelayanan dan pemberdayaan yang ada di dalam peraturan mengenai kelurahan. Serta menciptakan kantor pemerintahan yang terbuka, bebas dan dimiliki oleh warganya. Mimpi dari proyek ini adalah dengan mengubah 267 kantor kelurahan menjadi third place untuk warga kelurahannya. maka Jakarta memiliki 267 tempat yang masyarakatnya berkolaborasi dan berkembang dengan bantuan pemerintah DKI. Menguatkan setiap kelurahan dan meningkatkan rasa cinta terhadap kelurahannya akan menmbuat DKI Jakarta berkembang dari setiap sisinya tidak hanya dari pusat nya.

\section{REFERENSI}

Oldenburg, R. (2005). The Great Good Place. Philadelphia: Da Capo Press.

Lefebvre, H. (1992). The Production of Space. English: Wilwy-blackwell.

Bhabha, H. (1997). Liminality, Mimicry, Hybridity and Ambivalent in Literaty Speculation. English : Harvard University.

Foucault, M. (1966). Of Other Spaces, Heterotopias. MIT Press.

Soja, E. (1996). Thirdspace:Journeys to Los Angeles and Other Real-and-Imagined Places. Cambridge.

Tuan, Y. Fu. (1977). Space and Place. Minnesota Press.

Moore, J.F. (2012). Riccarton - The Art of the Third Place in a first suburb. Newzealand : Lincoln University.

Peraturan Pemerintah. (2005). Tentang Kelurahan (Nomor 73). Indonesia : Pemerintah Pusat 